\title{
The First-year Experience in Biological Engineering at LSU
}

\section{Dr. Marybeth Lima, Louisiana State University}

Marybeth is a Professor in Biological \& Agricultural Engineering and Director of the LSU Center for Community Engagement, Learning and Leadership. She co-authored the textbook Service-Learning: Engineering in Your Community (Oxford University Press) with Bill Oakes and is the author of Building Playgrounds Engaging Communities: Creating Safe and Happy Places for Children (LSU Press).

\section{Mr. Nicholas Patrick Totaro, Louisiana State University}

Nicholas Totaro graduated with a Master's in Biological and Agricultural Engineering at LSU under Dr. Daniel Hayes in 2015. Since 2016, Nick has been an instructor in the Department of Biological and Agricultural Engineering. His teaching duties include both courses in the first year sequence, as well as instrumentation and machine design in biological engineering. Nick also serves as the Undergraduate Program Coordinator and the Advisor of the Biological Engineering Student Organization. 


\title{
The first year experience in Biological Engineering at LSU
}

Nick Totaro and Marybeth Lima

\begin{abstract}
The biological engineering program has been offering a 2-course sequence for first year students since 1994. The purpose of these courses is to introduce students to the discipline, to teach fundamental skills in engineering methods, calculations, designs, and computer aided designs, and to build a sense of community through team work, communication skills, and service-learning. The tremendous increase of students in the program has led to shifts in the 2course sequence. This paper will present the 2-course sequence with a focus on recent changes to accommodate a higher student to faculty ratio, as well as course instructors working together to ensure a seamless transition between courses, including continuity in design projects. Specific changes include using peer mentors in large classes, a focus on career knowledge and skill building through these courses, and presenting the same human-centered design method across the courses.
\end{abstract}

\section{Introduction}

The Department of Biological and Agricultural Engineering at LSU offers an undergraduate degree in Biological Engineering (BE), a master's degree in Biological and Agricultural Engineering, and as of 2018, a Ph.D. in Biological Engineering.

The BE undergraduate degree is intended to be general and exposes students to problemsolving and design at the intersection of biology and engineering. Briefly, students are required to take multiple semesters of basic sciences courses in biology, chemistry, and physics, the traditional engineering science courses, and 11 biological engineering core courses in which students put basic and engineering science principles (along with other requirements) to use in biological engineering. At least one major course is offered every semester of the curriculum to encourage strong ties among students across the curriculum and expose students to almost all 12 faculty members. Technical and design electives are intended for students to gain expertise in one focus area of biological engineering. Focus areas include bioengineering, bioenvironmental engineering, bioprocessing, and biomechanical engineering.

When the curriculum was overhauled from a Biological \& Agricultural Engineering curriculum to a Biological Engineering curriculum in the early 1990s, first year courses were included in the new curriculum to ensure that students had opportunities to see the ways in which the fundamentals they were learning in basic sciences and math were applied in BE, to establish a community of learners, and to combat retention issues. The curriculum was overhauled in part to address a lack of enrollment, and the faculty wanted to ensure that students enrolled in the major would learn about BE in a supportive environment. 
The first two courses in the BE curriculum that comprise the "first year sequence" in the major are:

BE 1250 (offered each fall): 2 credit hours; 6 hrs. lab. Fundamentals of engineering design; presentation of an engineering design; graphical expression of engineering design using computer-aided drafting.

BE 1252 (offered each spring): 2 credit hours; 1 hr. lecture; 3 hrs. lab. Effect of variability and constraints of biological systems on engineering problem solving and design; engineering units; engineering report writing; oral report presentation; laboratory demonstration of biological engineering analysis.

Students are able to take these courses in either order, though the vast majority takes BE 1250 first. For a more in-depth look at the course sequence, consult Monroe et al. (2006) and Lima et al. (2001).

\section{Changes}

During the past 25 years, a number of changes have occurred that have influenced these courses. These changes include an increase in student population and interest in bioengineering, ABET accreditation, and increasing collaboration among instructors. Each of these changes and the corresponding change in course(s) is discussed below.

\section{Changes in population and interests of students.}

During the first year that these courses were offered, approximately 20 students enrolled in each course, and approximately 80 were enrolled $^{1}$ in the BE major. Today, about 100 students enroll in each course and approximately 300 students are enrolled in the undergraduate degree program.

The increase in student numbers is due to several factors; first, the high rate of students who are admitted to medical school with a BE major ( $85 \%$ ) drove an influx of pre-medical students into BE. ${ }^{2}$ Additionally, there is no biomedical engineering program at LSU; because BE is the closest major a student can get to biomedical engineering, students interested in this burgeoning field enter the BE program. Finally, the increase in student numbers can be partly attributable to the increase in overall student numbers at LSU; strong decreases in state funding have resulted in LSU admitting more students to the university to make up the difference in tuition. Since the economic downturn in 2008, LSU's undergraduate population

\footnotetext{
${ }^{1}$ This total includes BE majors and students enrolled in the University Center for the Freshman Year; the latter have declared their intention to major in BE and enroll in BE 1250 and 1252, but they haven't completed all requirements to get into the College of Engineering and thus officially enroll in $\mathrm{BE}$.

${ }^{2}$ A combination of the Department promoting this fact and word of mouth are responsible for this influx.
} 
has increased 13\%, from 22,176 in 2008 to 25,446 in 2017

(http://www.Isu.edu/bgtplan/facts/index.php).

Student interests today are overwhelmingly in bioengineering; as a whole, interests are much less diverse than they were 25 years ago, when approximately equal numbers of students were interested in each of the aforementioned specialty areas.

The biggest challenge in this area involves teaching much larger course sections. Multiple instructors have been added to share the student load, and numerous undergraduate teaching assistants are employed to provide peer support to students and to help with grading.

The high number of hours that students spent in lab in BE 1250 was also an issue with scheduling (the students take a number of 3-hour labs with basic science courses, and getting into these courses became increasingly difficult as student numbers grew) and with capacity of classroom space and available computers. In 2016, these issues, coupled with enhancements in online learning, led the faculty to change the course set up of BE 1250 from an all laboratory course to a combination lecture-laboratory course. As a result of this change, the course number changed as well:

$B E$ 1251: 1 hr. lec., 3 hrs. lab. Fundamentals of engineering design; presentation of an engineering design; graphical expression of engineering design using computer-aided drafting.

While not directly impacting the first year course sequence, recent faculty hires have a biomedical engineering background, which has resulted in the enhancement of bioengineeringbased design electives and departmental research.

\section{ABET accreditation}

Engineering Criteria 2000 changed accreditation from a "bean counting" exercise to one that focused on meeting expectations in a number of areas, including student learning outcomes (ak criteria).

In addressing a-k criteria, faculty looked at the overall program and decided that two criteria in particular were important to the first year design sequence:

(g) an ability to communicate effectively

(h) the broad education necessary to understand the impact of engineering solutions in a global, economic, environmental, and societal context.

BE 1250/1251 and 1252 were enhanced with respect to communication exercises (g) and 1252 was enhanced with respect to service-learning $(\mathrm{h})$, in which the students work in teams with a community partner to address a critical community need. 
These efforts were supported by the university-wide programs Communication Across the Curriculum, CxC (http://www.Isu.edu/academicaffairs/cxc/), which focuses on oral, written, technical, and visual communication skills, and the Center for Community Engagement, Learning, and Leadership (http://www.Isu.edu/academicaffairs/ccell/). Today, BE 1251 is designated by the university as communication intensive (technical and visual). BE 1252 is designated by the university as communication intensive (written and visual) and servicelearning. There is a plan underway (see Future plans for details) to offer BE 1251 as a servicelearning course.

\section{Increasing collaboration among instructors}

The faculty is collegial and long-term instructors of these courses have collaborated for years on these courses. However, starting two years ago, co-author Totaro began co-teaching both courses. This effort has led to greater continuity between the courses and a more seamless approach with objectives that cross courses, including an emphasis on career development, communication skill development, and design experiences. Specific examples include:

- A focus on visual communication which starts in BE 1251 (CAD drawing) and continues in BE 1252 (CAD drawing of playground design concepts). CAD formatting and best practices in drawing presented in 1251 are required/carried through in 1252.

- The same human-centered engineering design method (Lima and Oakes, 2014) presented across semesters.

- BE 1252 used to have a career assignment, consisting of three parts: an interview with a BE alum in an area in which the student was interested, research on the student's prospective career (general sources like the Occupational Outlook Handbook and technical research) and a plan for what the student would do to ready for their career during the ensuing 3-5 years. Student feedback indicated that students felt that the career assignment would be better in BE 1251 so that students compiled this information in their first semester to better prepare them for college even earlier. The increasing collaboration led to moving the career assignment to BE 1251; career information is carried forward in BE 1252 through a guest lecture on creating a resume that is delivered by the university's career services center. Students then submit their resume to career services and it must be approved by this center. As such, BE students complete the freshman sequence with a resume ready for submission for internship, employment, or REU experiences.

Also, all 1252 instructors are "on notice" with struggling students, for whom every effort is made to encourage success, directly through peer and instructor mentoring, or indirectly by ensuring that students have access to resources that they need, such as the university's Center for Academic Success.

\section{Conclusion and future plans}


Based on assessment from accreditation (where our overall assessment rubrics for student learning outcomes $g$ and $h$ during our last accreditation visit in 2015 were each 3.4/4.0, between meeting the outcome satisfactorily and meeting the outcome in an excellent manner), including exit interviews, the 2-course sequence seems to be successful in meeting its goals (we still need to assess changes from BE 1250 to 1251). The philosophy regarding first year courses and ensuring that students are knowledgeable about $B E$ and well-supported remains intact even though we are long "out of the woods" with low student numbers. Student to faculty ratio remains a challenge, but is manageable with departmental support for undergraduate teaching assistants.

One future plan is to designate BE 1251 as a service-learning course. The plan is to have students partner with local public schools to design math manipulatives for math tutoring at the school and to 3D print these manipulatives. The challenge with making 1251 servicelearning is that the course is already "packed" and the instructors do not want to alienate students with a high work load, especially given the other courses that they take.

If $B E 1251$ is taught as a service-learning course, then BE will offer three service-learning courses in the major; collectively, these service-learning courses enable BE students to automatically meet the credit hour requirement for LSU's Engaged Citizen program and would establish an in-major pipeline for this graduation distinction. The BE program already has a number of courses designated as communication intensive and has thus established an inmajor pipeline for the Distinguished Communicator graduation distinction. Another potential future plan with the coming of cheap, rapid 3D printing would be for student groups in BE 1252 to print prototypes of playground designs for interaction/presentation at the school.

In closing, our plan is to continue to offer high quality, student-centered instruction that positions students for future success in college and beyond, and that will position them to earn graduation distinctions in communication and engagement.

\section{References}

Lima, M., Drapcho, C., Walker, T., Bengtson, R. and Verma, L. 2001. A model for integrating [communication] skills across the biological engineering curriculum. International Journal of Engineering Education 17(1): 67-74.

Lima, M. and W. Oakes. 2014. Service-Learning: Engineering in Your Community, $2^{\text {nd }}$ edition. Oxford University Press, New York, NY. ISBN 978-0-19-992204-8.

Monroe, W., Mailander, M. and M. Lima. 2006. Focus on Experiential Education: A Freshman Engineering Program in Biological \& Agricultural Engineering. International Journal of Engineering Education 22(6): 1129-1138.

\section{Author bios}


Nicholas Totaro graduated with a B.S. in Biochemistry from LSU in 2011 and a masters degree in Biological \& Agricultural Engineering at LSU under Dr. Daniel Hayes in 2015. Since 2016, Nick has been an instructor in the Department of Biological and Agricultural Engineering. His teaching duties include both courses in the first year sequence, as well as instrumentation and machine design in biological engineering. Nick also serves as the Undergraduate Program Coordinator and the Advisor of the Biological Engineering Student Organization.

Marybeth Lima has served on the faculty of the Biological \& Agricultural Engineering Department at LSU since 1996. Her research interests include community-based engineering design. Marybeth directs the LSU Community Playground Project, in which college and elementary school students work together to design playgrounds at local schools. Lima was selected as an ASEE Fellow in 2012. 